\title{
Diagnostic Accuracy of GMHAT-PC Marathi: A Cross Sectional Study in Rural Maharashtra
}

\author{
Tendolkar VD ${ }^{1 *}$, Behere $\mathrm{PB}^{2}$, Sharma VK${ }^{3}$, Abhay Gaidhane ${ }^{4}$ and Quazi S Zahir ${ }^{5}$ \\ ${ }^{1}$ Deemed University, India
}

${ }^{2}$ D. Y. Patil University of Medical Sciences, India

${ }^{3}$ Department of Psychiatry, Chester University, UK

${ }^{4}$ Georgia Southern University, USA

${ }^{5}$ Associate Dean, Georgia Southern University, USA

Submission: December 09, 2017; Published: January 19, 2018

*Corresponding author: Tendolkar VD, Smt. Radhikabai Meghe Memorial College of Nursing, Datta meghe Institute of Medical Sciences (Deemed University), Sawangi (Meghe) Wardha, Maharashtra, India, Tel: +91-9850209588; Email: vaishali.ten@gmail.com

\begin{abstract}
Mental illnesses are significant contributors to the burden of disease. They cause loss of quality of life, economic loss and social dysfunction. Mental health problems at early stage remain unrecognized and untreated. There is tendency to conceal even severe psychiatric problems due to stigma. A large proportion of people with mental disorders around the world fail to receive appropriate help in spite of developments in new treatments for mental illnesses (psychological and social as well as medicinal). One of the important reasons is primary care health services providing inadequate training and poor skills for detecting and treating people with mental health problems. A comprehensive standardized assessment and identification of mental health problems at primary care level is essential in providing appropriate care to mentally ill. The Global Mental Health Assessment Tool-Primary Care Version (GMHAT/PC) is a computerized clinical assessment tool developed to assess and identify a wide range of mental health problems in primary care. This cross sectional study aims at assessing the diagnostic accuracy of the GMHAT-PC Marathi version for 500 persons reporting to psychiatric units. Results show overall alpha was 0.854 with the reliability coefficient of $r=0.921$. The overall ' $\mathrm{k}$ ' is 0.744 with sensitivity of 96.5 and specificity of $74.75 \%$. The computer assisted GMHAT/PC -Marathi shows good diagnostic accuracy for quick and comprehensive assessments and diagnoses of mental disorders for Marathi speaking population. This study may be considered a step towards quality and potentially equitable mental health assessment.
\end{abstract}

Keywords: Diagnostic accuracy; GMHAT-PC Marathi; Computerized assessment

\section{Introduction}

Mental health is a national wealth that needs to be preserved, protected and promoted for the growth and development of nations. Mental health problems affect all societies. Mental illnesses are significant contributors to the burden of disease. They lead to loss of quality of life, economic loss and social dysfunction, as well as cause misery to both the sufferers and their families. In some low income countries, the treatment gap for mental disorders can be higher than even 90\% [1-3].

World Health Organization estimated that mental and behavioural disorders account for about 12 percent of the global burden of diseases. Burden of mental disorders seen by the world is only a tip of iceberg. Various studies had shown that the prevalence of mental disorders were high in females, elderly, disaster survivors, industrial workers, children, adolescent and those having chronic medical conditions. A study conducted in Pune in 2012 reported the overall life time prevalence of mental disorders to be nearly 5 percent. Males were reported to be at higher risk. Major cause was depression followed by substance abuse and panic disorders. These findings were similar to results of the meta-analysis, which estimated the prevalence of mental disorders to be 5.8 percent among the Indian population. In 2010, a study conducted in NIMHANS, Bangalore reported that the burden of mental and behavioural disorders ranged from 9.5 to 102 per 1000 population. In 2000, a review of epidemiological studies estimated that the prevalence of mental disorders in India was 70.5 per 1000 in rural and 73 per 1000 in the urban population $[3,4]$.

Various Indian studies show that nearly 1 per cent of the Indian population suffers from severe mental disorders and 5-10 per cent from moderate disorders, requiring psychiatric help. The meta-analysis of available Indian studies carried out by Reddy and Chandrasekhar revealed the overall prevalence of mental disorders as 5.8\% among the population [5-7].

The mental health care in urban areas is at present limited to psychiatric hospitals and departments of psychiatry in medical colleges. Mental health problems at early stage remain 
unrecognized and untreated. There is tendency to conceal even severe psychiatric problems due to stigma [5].

Mental health problems are one of the leading causes of disability in the world. Early and accurate detection of mental health problems, followed by an appropriate treatment and management plan, may help to reduce the global burden on health and social care systems caused by mental disorders $[6,7]$.

A large proportion of people with mental disorders around the world fail to receive appropriate help in spite of developments in new treatments for mental illnesses (psychological and social as well as medicinal), and as a consequence suffer in silence. In developed countries this may be due to the stigma attached to mental illness, leading to reluctance to ask for help for any kind of mental health problem. Another important reason could be primary care health services providing inadequate training and poor skills for detecting and treating people with mental health problems [7-9].

Research studies have highlighted the lack of time and training available to general practitioners (GPs) and primary care workers for assessing the mental health of their patients. A poor provision of mental health care in low- and middle-income countries is often blamed on a lack of resources. It takes about six years to train a doctor, and a further three years to train as a psychiatrist. These countries therefore have few doctors and fewer psychiatrists, because of the high cost of medical education. A high proportion of these professionals emigrate to high-income countries. In a number of African countries there are no psychiatrists and in some only one or two [6,7].

\section{Background of the Study}

Mental illness constructs are not universal and are likely to be burdened with ethnocentric conceptualization. The burden of illness resulting from psychiatric and behavioural disorders is enormous. But it remains grossly under represented by conventional public health statistics, which focus on mortality rather than the morbidity or dysfunction. The psychiatric disorders account for 5 of 10 leading causes of disability as measured by years lived with a disability. At the international level, mental health is receiving increasing importance as reflected by the WHO focus on mental health as the theme for the World Health Day (4th October 2001), World Health Assembly (15th May 2001) and the World Health Report 2001 with Mental Health as the focus. At the national level, mental health policy has been the focus of Indian public health initiatives during last two decades. Currently India is implementing a national level programme of integrating mental health with primary health care, the largest such effort in a developing world $[9,10]$.

The Global Mental Health Assessment Tool-Primary Care Version (GMHAT/PC) has been developed to assist health professionals to make a quick and comprehensive standardized mental health assessment. It has proved to be a reliable and valid tool in a previous study involving GPs. Its use by other health professionals may help in detecting and managing mental disorders in primary care and general health settings [5,10,11].

There is a growing recognition both in developed and developing countries that comprehensive mental health services cannot be provided without the active involvement of primary care health teams. The role of primary care health professionals is crucial in: a) early detection of mental disorders, including psychotic illness; b) management of common mental disorders such as depression; c) getting advice on diagnosis and management of patients with mental illness from specialists; and d) providing care (specially for physical health) to people with severe and enduring mental illness in close liaison with specialist mental health professionals/teams. A proper assessment and identification of mental health problems at primary care level is, therefore, essential in providing appropriate care to people suffering from mental disorders in any community [11-13].

The Global Mental Health Assessment Tool -Primary Care Version (GMHAT/PC) is a computerized clinical assessment tool developed to assess and identify a wide range of mental health problems in primary care. It generates a computer diagnosis, a symptom rating, a self-harm risk assessment, and a referral letter $[11,14]$.

\section{Need for the Study}

In India, neuropsychiatric disorders are estimated to contribute to $11.6 \%$ of the global burden of disease [1]. There are approximately 28000 psychiatric beds (Including Government and private hospitals). OPD facilities are available through 4000 clinics. There are 3 psychiatrists, one psychiatric nurse, 0.4 psychologists and 0.3 for 1000000 people. General Practice doctors who are not trained in mental health, are 2.8 for 100000 people $[1,14]$.

There is a huge deficit of mental health services in Maharashtra, as in the rest of India. Inadequate government machinery to address the magnitude of mental health needs of communities has led to a surge in the number of private practitioners and rehabilitation centers. Over $70-80 \%$ of doctors in Maharashtra are in private practice, mostly working only in urban areas. Large numbers of government posts remain unfilled. There are no set standards of care for mental health practice in Maharashtra. The social context of people's lives is often not considered by the treating doctors. Standardized tools for clinical assessments do not exist. Diagnosis is left to the subjective evaluations of doctors. Aspects of preventive and promotive services are overlooked $[14,15]$.

Maharashtra shares $3.19 \%$ of the total mental illness of India. There are 7.27 beds per lac population in Maharashtra. The number of Government Psychiatric Institutions is 4, number of Private Psychiatric Institutions is 103, number of Medical Colleges with Department of Psychiatry is 15, number of general/ district hospitals providing psychiatric care is 23, number of districts covered by DMHP is 12 , and number of NGOs providing 
mental health care is 14 . Approximately 2.5 million new cases are registered every year and there are about 12 million follow up cases every year.

This study is designed to estimate the diagnostic accuracy of GMHAT-PC Marathi translated version for the diagnosis of mental illness in rural parts of Maharashtra. An effort is made to make available a comprehensive mental health assessment and diagnostic tool to all health professionals who care about, for and are directly or indirectly involved in the care of the mental health of general population $[15,16]$.

\section{Aim of the Study}

The study aims at estimating the diagnostic accuracy of Marathi version of Global Mental Health Assessment Tool Primary Care for various psychiatric disorders.

\section{Objectives of the study}

1. To assess the diagnostic accuracy of the GMHATs-PC Marathi version for the diagnosis of mental illness in people of age 15 years and above from rural Maharashtra.

\section{Review of Literature}

Mental health and illness are global health priorities. International reforms of mental health care systems repeatedly call for increased participation of a wide range of health, welfare, and disability professionals and organisations in providing services to people with mental disorders. There are increasing needs to improve mental health skills of all health-care professionals, improve coordination of services provided to consumers of mental health services and their and carers, and foster greater community interest and involvement in mental health issues [17].

Despite this, the roles of paramedics and contributions they can make to the care of the mentally ill in the wider continuum of health care have not been fully recognised. Mental illness is a global health crisis. It results in significant morbidity and is a major factor influencing the social determinants of health of individuals, families and communities. Approximately 450 million people worldwide are affected by mental, neurological, or behavioural problems at any time [18].

The performance of a new diagnostic test is frequently evaluated by comparison to a perfect reference test (i.e. a gold standard). In many instances, however, a reference test is less than perfect. Medical tests play a vital role in modern medicine not only for confirming the presence of disease but also to rule out the disease in individual patient. A test with two outcome categories such as test+ and test- is known as dichotomous, whereas more than two categories such as positive, indeterminate and negative called polytomous test. The validity of a dichotomous test compared with the gold standard is determined by sensitivity and specificity. These two are components that measure the inherent validity of a test [19]. The present study involved two activities namely translation and cultural adaptation of the GMHAT-PC from English to Marathi and validation of the translated Marathi computerized tool.

\section{Methodology}

\section{Research setting}

The study was conducted in the OPD of hospitals with a psychiatric unit and the Mental Health care institutes. The hospitals selected represent 3 regions of Maharashtra state of India. All the three institutes of mental health cater to both the rural and urban population and are located in rural areas of the respective districts.

\section{Study design}

Cross sectional study

\section{Participants}

Persons reporting to psychiatric treatment units. Persons reporting to the psychiatric department both OPD and IPD of selected hospitals, willing to participate in the study, and those who are available at the time of data collection are included in the study. Persons of both genders above 15 years of age are included. Mentally ill patients having known co-morbidity of systemic illness and unable to cooperate and uncooperative psychotic clients are excluded.

\section{Sample size}

500

\section{Material}

The material used for data collection in this study is Global Mental Health Assessment Tool - Primary Care Marathi Version [Computer Assisted GMHAT-PC-Marathi]. This tool covers diagnosis of wide range of mental disorders, provides guidelines for management and can provide a referral letter to the psychiatrist. In addition, the tool was found useful for the patients with chronic illness, heart disease and older adults. The tool is user friendly. In India and other countries computerized tools have shown positive response by the respondents.

\section{Global Mental Health Assessment Tool (GMHAT- PC)}

The program is based on the Delphi (Borland) System and does not need any other software programming support. The GMHAT - PC software runs on following operating system, Windows Xp, Windows Vista, Windows 7 and Windows 8.

The GMHAT/PC is a computerised clinical assessment tool developed to assess and identify mental health problems in primary and general health care. The assessment program starts with basic instructions giving details of how to use the tool and rate the symptoms. The following screens consist of a series of questions leading to acomprehensive yet quick mental state assessment, focusing sequentially on the following symptoms or problems. 


\section{Translation of the Tool}

For the translation of tool into Marathi; permission of the original developer was taken. The translation process included standard protocol of forward translation by investigator and two other translators independently, correction by the language expert, and a heterogeneous focus group discussion followed by the reverse translation by two independent linguists and finally four focused interviews.

\section{Method of Data Collection}

The subjects for the study were selected purposively from among those who reported to the psychiatric OPD and IPD. The subjects were explained about the study and written informed consent was taken from them. The investigator collected data by conducting face to face computer assisted structured interview by usingGMHAT-PC Marathi version. The psychiatrist, unaware of the GMHAT-PC's reports; then immediately after the data collection; performed the assessment of each subject. Psychiatrist's (Clinical) diagnosis was considered as 'Gold standard'. The clinical diagnosis by the psychiatrist was entered in the computer software. Printed report of each subject was taken. The two diagnoses were matched Table 1: Distribution of subjects according to their demographic characteristics.

\begin{tabular}{|c|c|c|c|}
\hline $\begin{array}{l}\text { Demographic } \\
\text { Characteristics }\end{array}$ & Categories & Frequency & $\%$ \\
\hline \multirow{5}{*}{ Age } & a) $15-30$ & 147 & 29.4 \\
\hline & b) $31-45$ & 212 & 42.4 \\
\hline & c) $46-60$ & 105 & 21 \\
\hline & d) $61-75$ & 32 & 6.4 \\
\hline & e) $75-90$ & 4 & 0.8 \\
\hline \multirow{2}{*}{ Gender } & a) Male & 284 & 56.8 \\
\hline & b) Female & 216 & 43.2 \\
\hline \multirow{5}{*}{ Marital Status } & a) Married & 351 & 70.2 \\
\hline & b) Unmarried & 102 & 20.4 \\
\hline & c) Divorcee & 17 & 3.4 \\
\hline & d) Separated & 15 & 3 \\
\hline & e) Widow/Widower & 15 & 3 \\
\hline \multirow{3}{*}{ Living Status } & a) With Family & 493 & 98.6 \\
\hline & b) With Friends & 1 & 0.2 \\
\hline & c) Single & 6 & 1.2 \\
\hline \multirow{2}{*}{ IPD/OPD } & a) OPD & 426 & 85.2 \\
\hline & b) IPD & 74 & 14.8 \\
\hline \multirow{3}{*}{ Region of Data Collection } & a) Wardha & 236 & 47.2 \\
\hline & b) Nanded & 210 & 42.0 \\
\hline & c) Barshi & 54 & 10.8 \\
\hline
\end{tabular}

For the purposes of finding inter-rater reliability and feasibility for use of the tool, 30 subjects were simultaneously rated by the investigator and another psychiatric nurse who was trained for use of GMHAT-PC software.

\section{Ethical Considerations}

The study was conducted only after the sanction by the Institutional Ethical Committee of the University. Written consent was taken from the participants before recruiting them. They were explained about the study in the language they understand; i.e. Marathi. No harm of any nature to the participants is foreseen in the study.

\section{Observations and Results}

The mean age of the participants was $45+2.03$ yrs. There were $56.8 \%$ males and $43.2 \%$ females. $70.2 \%$ subjects were married, $20.4 \%$ were unmarried, $3.4 \%$ were divorcee, $3 \%$ each were separated and widowed/widower respectively. The subjects belonged to 20 districts (314 villages) in Maharashtra (Table1). 
History of physical abuse was reported by $11.4 \%, 12 \%$ reported emotional abuse and $1.2 \%$ reported sexual abuse. $36 \%$ reported family history of mental illness. $8 \%$ reported history of suicide in the family. $61.8 \%$ reported past history of mental illness and $38.2 \%$ had this episode as the first one. $6.8 \%$ had history of epilepsy. $1.6 \%$ had mild to moderate mental retardation (Table 2).

Table 2: Background information of participants regarding Mental Illness.

\begin{tabular}{|c|c|c|c|}
\hline $\begin{array}{l}\text { Background } \\
\text { Information }\end{array}$ & Categories & Frequency & $\%$ \\
\hline \multirow{3}{*}{ History of abuse } & a) Physical & 57 & 11.4 \\
\hline & b) Emotional & 60 & 12 \\
\hline & c) Sexual & 6 & 1.2 \\
\hline \multirow{2}{*}{$\begin{array}{l}\text { History of mental } \\
\text { illness in the family }\end{array}$} & a) Yes & 180 & 36 \\
\hline & b) No & 320 & 64 \\
\hline \multirow{2}{*}{$\begin{array}{l}\text { History of suicide in the } \\
\text { family }\end{array}$} & a) Yes & 40 & 8 \\
\hline & b) No & 460 & 92 \\
\hline \multirow{3}{*}{$\begin{array}{l}\text { Duration of recent } \\
\text { problems }\end{array}$} & a) Up to 1 year & 423 & 84.6 \\
\hline & b) $1-5 \mathrm{yrs}$ & 76 & 15.2 \\
\hline & $\begin{array}{c}\text { c) } \\
\text { More than } 5 \\
\text { years }\end{array}$ & 1 & 0.2 \\
\hline \multirow{2}{*}{$\begin{array}{l}\text { Past History of mental } \\
\text { Illness }\end{array}$} & a) Yes & 309 & 61.8 \\
\hline & b) No & 191 & 38.2 \\
\hline \multirow{2}{*}{ History of epilepsy } & a) Yes & 34 & 6.8 \\
\hline & b) No & 466 & 93.2 \\
\hline \multirow{4}{*}{$\begin{array}{l}\text { History of mental } \\
\text { Retardation }\end{array}$} & a) Yes & 8 & 1.6 \\
\hline & b) No & 492 & 98.4 \\
\hline & $\begin{array}{l}\text { i) Mild to Mod. } \\
\text { MR }\end{array}$ & 8 & 1.6 \\
\hline & ii) Severe MP & 0 & 0.0 \\
\hline
\end{tabular}

Reliability statistics between computer diagnosis and the clinical diagnosis (Gold standard-the psychiatrist's diagnosis) reveals that the computer diagnosis and the clinical diagnosis matched for 387 as cases (psychiatric illness) and for 74 as no cases (No mental illness). The Cronbach's alpha coefficient estimated for the given crosstabs was 0.854 with the reliability coefficient of $r=0.921$. This value is much higher than the acceptable $r=0.70$ for a tool to be reliable. The ' $\mathrm{k}$ ' value is 0.744 which is acceptable Table 5: Diagnostic Accuracy \& Level of Agreement of GMHAT-PC Mara indicating that the tool is accurate to use for the diagnosis of psychiatric illness among the selected population (Table 3).

Table 3: Diagnostic Accuracy for diagnosis of No Mental Illness.

\begin{tabular}{|c|c|c|c|c|}
\hline \multirow{2}{*}{$\begin{array}{c}\text { GMHAT-PC } \\
\text { Diagnosis }\end{array}$} & & \multicolumn{2}{|c|}{ Clinical Diagnosis } & \multirow{2}{*}{ Total } \\
\cline { 2 - 4 } & $\begin{array}{c}\text { No Mental } \\
\text { Illness }\end{array}$ & 74 & 25 & 99 \\
\hline & $\begin{array}{c}\text { Mental } \\
\text { Illness }\end{array}$ & $\begin{array}{c}\text { Mental } \\
\text { Illness }\end{array}$ & \\
\hline \multirow{2}{|c|}{ Total } & 88 & 387 & 401 \\
\hline \multicolumn{2}{|c|}{} & 812 & 500 \\
\hline
\end{tabular}

The overall sensitivity of the tool was found to be $96.51 \%$ $(94.21 \%$ to $98.08 \%)$ (Assumed sensitivity $=90 \%$ ) and specificity is $74.75 \%$ (65.02\% to $82.94 \%$ ) (Assumed specificity = 80\%). The Positive likelihood Ratio $=3.82$ (2.72 to 5.37), Negative Likelihood Ratio $=0.05$ (0.03 to 0.08), Positive Predictive Value $=93.93 \%$ $(91.17 \%$ to $96.04 \%)$ and Negative Predictive Value $=84.09 \%$ $(74.75 \%-91.02 \%)$. The sensitivity and specificity values are compatible with assumed levels thus indicating accuracy of the tool (Table 4).

Table 4: All tests values at $95 \%$ confidence interval.

\begin{tabular}{|c|c|c|}
\hline Statistic & Value & 95\% CI \\
\hline Sensitivity & $84.09 \%$ & $74.75 \%$ to $91.02 \%$ \\
\hline Specificity & $93.93 \%$ & $91.17 \%$ to $96.04 \%$ \\
\hline Positive Likelihood Ratio & 13.86 & 9.38 to 20.48 \\
\hline Negative Likelihood Ratio & 0.17 & 0.10 to 0.27 \\
\hline Disease prevalence & $17.60 \%$ & $14.36 \%$ to $21.23 \%$ \\
\hline Positive Predictive Value & $74.75 \%$ & $65.02 \%$ to $82.94 \%$ \\
\hline Negative Predictive Value & $96.51 \%$ & $94.21 \%$ to $98.08 \%$ \\
\hline
\end{tabular}

The kappa ' $\mathrm{k}$ ' value for 'No Mental Illness' is 0.744 ; for anxiety disorders is 0.745 ; for alcohol abuse is 0.0 .867 ; for depression is 0.796 ; for psychosis is 0.806 ; for mania is 0.829 ; for organic mental disorders is 0.746; for phobia is 0.664 ; for PTSD is 0.908 ; for personality disorders is 0.932 ;for somatoform disorders is 0.664 ; for OCD is 1 ; and for psychosis with depression is 0.737 indicating that the tool is accurate to use for the diagnosis of most of the mental disorders (Table 5).

Table 5: Diagnostic Accuracy \& Level of Agreement of GMHAT-PC Marathi with Clinical Diagnosis.
\begin{tabular}{|c|c|c|c|c|}
\hline Diagnosis & ' $\mathrm{k}$ ' & Sensitivity & Specificity & PPV \\
\hline Anxiety (31) & 0.745 & $75.61 \%$ & $98.04 \%$ & $77.50 \%$ \\
& & $59.70 \%-87.64 \%$ & $96.31 \%-99.10 \%$ & $61.55 \%-89.16 \%$ \\
\hline Alcohol abuse (57) & 0.867 & $96.61 \%$ & $97.05 \%$ & $81.43 \%$ \\
\hline $\begin{array}{c}\text { Depression } \\
\text { (71) }\end{array}$ & 0.796 & $78.29 \%-99.59 \%$ & $95.01 \%-98.42 \%$ & $70.34 \%-89.72 \%$ \\
\hline Psychosis & 0.806 & $69.01 \%-86.79 \%$ & $78.89 \%$ & $78.89 \%$ \\
$(119)$ & $80.95 \%$ & $89.01 \%-86.79 \%$ & $69.01 \%-86.79 \%$ \\
\hline
\end{tabular}


JOJ Nursing \& Health Care

\begin{tabular}{|c|c|c|c|c|}
\hline Mania (10) & 0.829 & $\begin{array}{c}83.33 \% \\
51.59 \%-97.91 \%\end{array}$ & $\begin{array}{c}99.59 \% \\
98.53 \%-99.95 \%\end{array}$ & $\begin{array}{c}83.33 \% \\
51.59 \%-97.91 \%\end{array}$ \\
\hline $\begin{array}{l}\text { Organic Mental disorders } \\
\qquad(6)\end{array}$ & 0.746 & $\begin{array}{c}75.00 \% \\
34.91 \%-96.81 \%\end{array}$ & $\begin{array}{c}99.40 \% \\
98.54 \%-99.95 \%\end{array}$ & $\begin{array}{c}75.00 \% \\
34.91 \%-96.81 \%\end{array}$ \\
\hline Phobia (3) & 0.664 & $\begin{array}{c}100.00 \% \\
29.24 \%-100.00 \%\end{array}$ & $\begin{array}{c}99.40 \% \\
98.25 \%-99.88 \%\end{array}$ & $\begin{array}{c}50.00 \% \\
11.81 \%-88.19 \%\end{array}$ \\
\hline PTSD (5) & 0.908 & $\begin{array}{c}100.00 \% \\
47.82 \%-100.00 \%\end{array}$ & $\begin{array}{c}99.80 \% \\
98.88 \%-99.99 \%\end{array}$ & $\begin{array}{c}83.33 \% \\
35.88 \%-99.58 \%\end{array}$ \\
\hline Personality disorders (7) & 0.932 & $\begin{array}{c}100.00 \% \\
59.04 \%-100.00 \%\end{array}$ & $\begin{array}{c}100.00 \% \\
59.04 \%-100.00 \%\end{array}$ & $\begin{array}{c}87.50 \% \\
47.35 \%-99.68 \%\end{array}$ \\
\hline Somatoform disorders (6) & 1 & $\begin{array}{c}100.00 \% \\
99.26 \%-100.00 \%\end{array}$ & $\begin{array}{c}100.00 \% \\
99.26 \%-100.00 \%\end{array}$ & $\begin{array}{c}100.00 \% \\
98.25 \% 99.88 \%\end{array}$ \\
\hline $\begin{array}{l}\text { Organic Mental disorders } \\
\qquad(6)\end{array}$ & 0.746 & $\begin{array}{c}75.00 \% \\
34.91 \%-96.81 \%\end{array}$ & $\begin{array}{c}99.40 \% \\
98.54 \%-99.95 \%\end{array}$ & $\begin{array}{c}75.00 \% \\
34.91 \%-96.81 \%\end{array}$ \\
\hline Eating disorders (0) & -- & $\begin{array}{c}.00 \% \\
0.00 \%-97.50 \%\end{array}$ & $\begin{array}{c}.00 \% \\
0.00 \%-97.50 \%\end{array}$ & -- \\
\hline Sleep Disorders (0) & -- & -- & $\begin{array}{c}99.80 \% \\
98.89 \%-99.99 \%\end{array}$ & $\begin{array}{c}0.00 \% \\
0.00 \% \text { to } 97.50 \%\end{array}$ \\
\hline $\begin{array}{l}\text { OCD } \\
(6)\end{array}$ & 1 & $\begin{array}{c}100.00 \% \\
54.07 \%-100.00 \%\end{array}$ & $\begin{array}{c}100.00 \% \\
99.26 \%-100.00 \%\end{array}$ & $\begin{array}{c}100.00 \% \\
54.07 \%-100.00 \%\end{array}$ \\
\hline $\begin{array}{l}\text { Psychosis with Depression } \\
\qquad(18)\end{array}$ & 0.737 & $\begin{array}{c}81.82 \% \\
59.72 \%-94.81 \%\end{array}$ & $\begin{array}{c}98.33 \% \\
96.73 \%-99.27 \%\end{array}$ & $\begin{array}{c}69.23 \% \\
48.21 \%-85.67 \%\end{array}$ \\
\hline Eating disorders $(0)$ & -- & $\begin{array}{c}0.00 \% \\
0.00 \%-97.50 \%\end{array}$ & $\begin{array}{c}0.00 \% \\
0.00 \%-97.50 \%\end{array}$ & -- \\
\hline Sleep Disorders (0) & -- & -- & $\begin{array}{c}99.80 \% \\
98.89 \%-99.99 \%\end{array}$ & $\begin{array}{c}0.00 \% \\
0.00 \% \text { to } 97.50 \%\end{array}$ \\
\hline $\begin{array}{l}\text { OCD } \\
(6)\end{array}$ & 1 & $100.00 \% 54.07 \%-100.00 \%$ & $\begin{array}{c}100.00 \% 100.00 \% \\
99.26 \%-100.00 \%\end{array}$ & $\begin{array}{l}100.00 \% 100.00 \% \\
54.07 \%-100.00 \%\end{array}$ \\
\hline $\begin{array}{l}\text { Psychosis with Depression } \\
\text { (18) }\end{array}$ & 0.737 & $\begin{array}{c}81.82 \% \\
59.72 \%-94.81 \%\end{array}$ & $\begin{array}{c}98.33 \% \\
96.73 \%-99.27 \%\end{array}$ & $\begin{array}{c}69.23 \% \\
48.21 \%-85.67 \%\end{array}$ \\
\hline
\end{tabular}

The sensitivity and specificity values for all of the above conditions are compatible with assumed levels thus indicating accuracy of the tool. The GMHAT-PC Marathi version is simple to use and with short training can be used by any health professional with average knowledge of mental health. It took an average time of 13.4 minutes for interview and is found feasible for routine assessments in psychiatric OPD despite the workload. Both patients and nurses found the GMHAT/PC Marathi version acceptable and useful in making a quick and comprehensive mental health assessment.

The clients reported that they felt that they were asked all questions related to what they go through. This was particularly so with the items related to eating disorders, fear, personality problems, worries and stress. None of the subjects declined to participate in the study and all gave positive feedback.

\section{Discussion}

The process of translation incorporates most of the mandatory elements of translation and cultural adaptation recommended by the researchers and authorities for the mental health assessment tools. The investigator in this study has gone a step further by conducting focus group discussion and focus interviews to broaden the applicability of GMHAT-PC Marathi version to most population in Maharashtra.

The findings of the present study are supported by the findings in other studies with GMHAT-PC.

Palanisamy et al. [20] in their study, reported the levels of agreement between the consultants and the GMHAT/PC for a diagnosis of mental illness showed a kappa value of 0.72 (95\% CI $0.62-0.83)$. There is good sensitivity (0.77) and excellent 
specificity (0.96), with GMHAT/PC correctly identifying 67 out of 86 subjects with mental illness, and 80 out of 83 as without. The GMHAT/PC correctly identified 20 out of 33 patients with an organic illness, and 134 out of 136 as without. The feedback of interviewers and participants was satisfactory. The average time taken was 14 minutes [20].

Sharma et al. [21] in a feasibility study among nurses reported the mean age (standard deviation) in the male group was 69.5(10.5) years and for the female group it was 61.0(12.3) years. The age range was $28-87$ years. The mean time (standard deviation) taken for the administering GMHAT/PC by nurses in the male group was 13.3(6.4) minutes and in the female group it was 14.9 (10.1) minutes. There was an excellent level of agreement between the nurses (GMHAT/PC) diagnosis and the psychiatrist diagnosis of mental illness with the correlation coefficient i.e. Kappa 0.76 [95\% CI $(0.61,0.91)]$. There is good sensitivity of 0.73 $95 \%$ CI $(0.56,0.90)$ and excellent specificity of 0.98 [95\% CI $(0.95$, 1.00)] [21].

\section{Conclusion}

The findings of this study are encouraging and support the view that other health professionals, particularly psychiatric nurses and possibly others can use the computer assisted GMHAT / PC -Marathi to make valid, quick and comprehensive assessments and diagnoses of mental disorders for Marathi speaking people. GMHAT/PC- Marathi in psychiatric settings appears to have good sensitivity and specificity. The mean duration of the interview was around 13.4 minutes which makes it feasible for routine use in the outpatient departments. Both patients and psychiatric nurses found the GMHAT/PC Marathi not only acceptable but also useful for comprehensive mental health assessment.

\section{Implications for Future Research and Practice}

GMHAT-PC provides measurement of symptoms. It will also help health professionals to choose appropriate care pathways. GMHAT/PC has been translated into various languages. Further studies are in progress in several countries to assess its validity and usefulness in different cultures and varied settings. GMHAT/ PC could help health care professional across the world to make accurate mental health assessments. This will enable them to provide mental health services to a larger population.

\section{References}

1. World Health Organization (2015) Mental health atlas, Geneva, Switzerland.

2. Government of Maharashtra (2002) A report on 'disabled persons' based on data collected in state sample of 58th round of national sample survey.

3. Sharma VK, Lepping P, Krishna M, Durrani S, Copeland JR, et al (2008) Mental health diagnosis by nurses using the Global Mental Health Assessment Tool: a validity and feasibility study. $\mathrm{Br} \mathrm{j}$ gen pract 58(551): 411-416.
4. Sharma VK, Krishna M, Lepping P, Palanisamy V, Kallumpuram SV, et al. (2010) Validation and feasibility of the Global Mental Health Assessment Tool-Primary Care version (GMHAT/PC) in older adults. Age Ageing 39(4): 496-499.

5. Sharma VK, Copeland JR (2009) Detecting mental disorders in primary care. Ment Health Fam Med 6(1): 11-13.

6. Bodke P, Bhosle R (2014) Prevalence of psychiatric illness in rural Maharashtra. Medpulse-International Medical Journal 1(3): 119-122.

7. Shah B, Rashmi P, Narender K, Khanna T, Ravinder S (2012) Mental health research in India (technical monograph on icmr mental health studies).

8. Balbir SD, Pawar A (2012) An epidemiological study of mental disorders at Pune, Maharashtra. Indian J Community Med 37(2): 116121.

9. Sinha S (2014) Correlation of outcome of global mental health assessment tool (GMHAT- PC) in assessment of psychiatric patients as compared to the psychiatrist's diagnosis in a primary care of central India.

10. Sharma VK, Lepping P, Cummins AG, Copeland JR, Parhee R, et al. (2004) The Global Mental Health Assessment Tool - Primary Care version (GMHAT/PC): development, reliability and validity. World Psychiatry 3(2): 115-119.

11. Sharma VK, Copeland JR (2009) Detecting mental disorders in primary care. Ment Health Fam Med 6(1): 11-3.

12. Krishna M, Lepping P, Sharma VK, Copeland JR, Lockwood L (2009) Epidemiological and clinical use of GMHAT-PC (Global Mental Health Assessment Tool-Primary Care) in cardiac patients. Clin Pract Epidemiol Ment Health 5: 7.

13. Chinman M, Young As, Schell T, Hassell J, Mintz J (2004) Computerassisted self-assessment in persons with severe mental illness. J Clin Psychiatry 65(10): 1343-1351.

14. Mental Health Atlas, Department of mental health and substance abuse, World Health Organization, Geneva, Switzerland.

15. Meeting with Maharashtra mental health policy makers. Gáborgombos.

16. Bhui K, Mohamud S, Warfa N, Craig TJ, Stansfeld SA (2003) Cultural adaptation of mental health measures: improving the quality of clinical practice and research. British Journal of Psychiatry 183: 184-186.

17. Sharma VK, Jagawat S, Midha A, Jain A, Tambi A, et al. (2010) The Global Mental Health Assessment Tool-validation in Hindi: A validity and feasibility study. Indian J Psychiatry 52(4): 316-319.

18. Murali K, Peter L, Vimal KS, John RM, Feasibility of using a computer assisted diagnostic interview by nurses for patients attending Cardiac Rehabilitation Clinics and to examine the level of agreement between the GMHAT/PC diagnosis and a Psychiatrist clinical diagnosis unpublished article).

19. Sharma VK, Durrani S, Sawa M, Copeland JRM, Abou-Saleh MT, et al (2013) Arabic version of the Global Mental Health Assessment ToolPrimary Care version (GMHAT/PC): a validity and feasibility study. EMHJ 19(11): 905-908.

20. Vikram P, Vimal KS, Murali K, Peter L, Sen VK, et al. (2010) Validation and feasibility of Global Mental Health Assessment Tool-Primary care version (GMHAT/PC) in the older adults. Published by Oxford University Press on behalf of the British Geriatrics Society.

21. Sharma VK, Lepping P, Cummins AG, Copeland JR, Parhee R, et al. (2004) The Global Mental Health Assessment Tool-Primary Care Version (GMHAT/PC). Development, reliability and validity. World Psychiatry 3(2): 115-119. 
This work is licensed under Creative Commons Attribution 4.0 License

BY DOI: 10.19080/JOJNHC.2018.06.555679
Your next submission with Juniper Publishers will reach you the below assets

- Quality Editorial service

- Swift Peer Review

- Reprints availability

- E-prints Service

- Manuscript Podcast for convenient understanding

- Global attainment for your research

- Manuscript accessibility in different formats

( Pdf, E-pub, Full Text, Audio)

- Unceasing customer service

Track the below URL for one-step submission https://juniperpublishers.com/online-submission.php 